\title{
Influence of the Primary and Secondary Lower Leg War Amputations on the Length of Hospitalization and Rehabilitation
}

\begin{abstract}
Zlata Jelačić
University of Sarajevo, Faculty of Mechanical Engineering, Department of Biomechanics, Vilsonovo šetalište 9, 71000 Sarajevo, Bosnia and Herzegovina
\end{abstract}

\begin{abstract}
Objective: To analyze the influence of war amputations on the rehabilitation length we have tried to find a correlation between different stages of the rehabilitation process and the kind of amputation that has been performed.
\end{abstract}

Methods: Therefore we have analyzed the data of 36 patients with knee amputation due to war injuries. The average age was 35.42 years. Most patients were wounded by explosive land mines $(94.4 \%)$, others by projectiles. In $\mathbf{2 . 8 \%}$ of cases there was a bilateral amputation.

Results: The limb was amputated on the day when the injury (primary amputation) occurred in 30 patients $(83.3 \%)$. Secondary amputation after an attempt to save a severely injured limb was performed in 6 patients $(16.7 \%)$, on average $4.61 \pm 11.67$ days after injury. Reamputation was necessary in 6 cases $(16.7 \%)$. The average length of time between rehabilitation to the fitting of prosthetics, was for primary amputations $36.25 \pm 14.97$ days, in secondary $32 \pm 17.8$ days, and in reamputations $68.66 \pm$ 33.52 days.

Conclusion: There is no statistically significant correlation between the duration of rehabilitation to prosthetics fitting and time between injury and amputation ( $r=\mathbf{- 0 . 1 0 2})$. Attempt to save the limb in severe lower leg war injuries and secondary amputation thereafter did not significantly affect the later course of rehabilitation and prosthetic fitting.

Keywords: leg injuries; amputation; rehabilitation; hospitalization; length of rehabilitation; military medicine; war.

\section{INTRODUCTION}

In the circumstances of war injuries, amputation is a necessary operation to save the life of the injured. Explosive and gunshot wounds have a devastating effect on tissues and lead to severe damage to many structures. The progress of reconstructive surgery is in severe injuries of lower extremities enabled impressive attempts in saving extremities from amputation, which represents severe loss on the physical, psychosocial and professional plan. However, performing such operations is not always without complications compared to immediately performed knee amputation. In some cases despite all attempts to save the extremities, it is inevitable to perform secondary amputation as well. Dagum et al. found that the quality of life is significantly lower in persons with primary and secondary lower leg amputation as compared to those in which there was an attempt to save the extremities succeeded after severe, open fractures of the tibia. Also, research states that in $92 \%$ of cases, an injured person would rather accept an attempt to save their leg than an amputation at any stage of treatment [1]. Re-amputation is also necessary in some cases of war surgery, which is performed for the sake of formation of a functional stump. These are all important factors that affect the duration, the course and outcome of treatment and rehabilitation of patients with severe injuries of lower extremities and knee amputations. Researchers cite multiple factors that are potentially associated and have an impact on prosthetics, duration and outcome of treatment in persons with knee amputations [2-4]. However, there are fewer reports of amputations due to war injuries, the impact of secondary amputations on length duration of rehabilitation, functional training, including prosthetics and walking training. The aim of our work was to investigate the structure (according to sex, age, cause and side of amputation) of severe war injuries to the lower extremities due to which the primary and secondary lower legs were made amputation, as well as to examine whether the secondary amputation has impact on the duration of hospital treatment and rehabilitation to training in relation to patients with primary knee amputations.

\section{METHODS}

In our paper, we analyzed data on 36 people with explosive and gunshot wounds due to war, where knee amputation has been performed. The sample was obtained by the method random selection from the hospital protocol. From the investigation all patients who were hospitalized and transferred to another clinic due to complications on other 
ISSN (online): 2581-3048

Volume 6, Issue 1, pp 88-90, January-2022

https://doi.org/10.47001/IRJIET/2022.601016

organs and organ systems were excluded. All patients who came for the renewal of treatment or correction of prosthetic devices were also excluded from the study, as well as those in whom amputation was not caused by war injury. Average age of respondents in our sample was $35.42 \pm 10.45$ years, and the age ranged from 20 to 59 years of age. All subjects were included in a complex rehabilitation program after the primary and secondary lower leg amputations. The treatment was carried out by a rehabilitation team: a physiatrist, orthopedic surgeon, physiotherapist, occupational therapist, medical nurse, master prosthetist, and, if necessary, specialists from other areas of medicine.

\section{RESULTS}

In 34 or $94.4 \%$ of the injured in our sample, the lower leg amputation was performed due to explosive injuries. They were all men and most often belonged to the age groups between 25 and 35 years. In one case (2.8\%), both lower extremities were amputated (Table 1).

Table 1: Sample characteristics

Sample characteristics $(n=36)$

\begin{tabular}{|c|c|c|c|}
\hline & Characteristics & Number & Percentage \\
\hline \multirow{6}{*}{ Age } & average age & $\begin{array}{c}35,42 \pm \\
10,45\end{array}$ & \\
\hline & up to 25 years old & 8 & 22,2 \\
\hline & $25-34$ & 11 & 30,5 \\
\hline & $35-44$ & 10 & 27,8 \\
\hline & $45-54$ & 5 & 13,9 \\
\hline & over 55 & 2 & 5,6 \\
\hline \multirow{2}{*}{ Sex } & women & 0 & \\
\hline & men & 36 & 100 \\
\hline \multirow{2}{*}{ Cause } & explosions (mines) & 34 & 94,4 \\
\hline & projectiles & 2 & 5,6 \\
\hline \multirow{3}{*}{$\begin{array}{l}\text { Amputation } \\
\text { side }\end{array}$} & left & 19 & 52,78 \\
\hline & right & 16 & 44,42 \\
\hline & bilateral & 1 & 2,8 \\
\hline
\end{tabular}

The limb was amputated on the same day as the injury in 30 persons $(83.33 \%)$. In others $(16.7 \%)$, a secondary amputation has been performed after as an attempt to save the limb (Table 2).

Table 2: Structure of lower leg amputations Structure of the war lower leg amputations $(n=36)$

\begin{tabular}{ccccc}
\hline \multirow{2}{*}{ Amputations } & & Nr. & Percentage & $\begin{array}{c}\text { Time till } \\
\text { prosthetisation } \\
\text { (days) }\end{array}$ \\
\hline Primary & no reamputation & 25 & 69,5 & \\
& with amputation & 5 & 13,8 & $36,25 \pm 14,97$ \\
& total & 30 & 83,3 & \\
\hline
\end{tabular}

\begin{tabular}{ccccc} 
Secondary & No reamputation & 5 & 13,9 & \\
& With amputation & 1 & 2,8 & \\
& total & 6 & 16,7 & 32 \\
\hline Total & 36 & 100 & 37,06 \\
\hline Reamputations & & 6 & 16,7 & $68,66 \pm 33,52$ \\
\hline
\end{tabular}

Reamputation was necessary in 6 cases or at $16.7 \%$ of patients (Table 2). The results of our research show that in subjects where the limb was amputated the same day it the injury happened, the average length of time between the rehabilitation and the fitting of prosthetics and training for gait function with definitive prosthesis was $36.25 \pm 14.97$ days. In subject with secondary amputation, which was performed after a failed attempt to save the extremity after severe injuries to the lower leg, that time was $32 \pm 17.8$ days. In patients with reamputation, the length of hospital treatment (rehabilitation after reamputation) to the fitting of prosthetics was $68.66 \pm$ 33.52 days (Table 2). Correlation between the length of rehabilitation and time from the injury to the amputation in the case of immediate amputation after injury was the shortest and took $4.61 \pm 11.67$ days (Table 3 ).

Table 3: Correlation between the length of rehabilitation and time from the injury to the amputation

\begin{tabular}{lccc}
\hline & \multicolumn{2}{c}{ Amputations } \\
& & Primary & Secondary \\
\hline $\begin{array}{l}\text { Number of patients } \\
\text { Time from the start of }\end{array}$ & 30 & 6 \\
rehabilitation & till & & \\
prosthetisation (days) & & 36,25 & 32 \\
SD & & 14,97 & 17,8 \\
r & & $-0,102$ & $\mathrm{p}>0,05$ \\
Time from the injury & till & & $4,61 \pm$ \\
amputation (days) & & immediately & 11,67 \\
\hline
\end{tabular}

\section{DISCUSSION}

The goal of modern treatment of people with severe injuries of lower extremities is to achieve the best possible quality of life. When it is not possible to save a limb, it is important to restore its shape and function. In this paper, we analyzed patient data with severe war injuries to the lower extremities due to which knee amputation was performed, as well as the influence of primary and secondary amputations on the duration of time between hospital treatment and prosthetic fitting, functional training and training for basic social functions. The results of the research show that within the war, explosive or shutter wounds are the most common causes of knee amputations, which is in agreement with reports by other authors [5]. In our sample are all subjects with knee amputations were men as there is greater prevalence of men in the war. The wounding is logical and is stated in other reports 
ISSN (online): 2581-3048

Volume 6, Issue 1, pp 88-90, January-2022

https://doi.org/10.47001/IRJIET/2022.601016

[5]. The highest percentages of injured subjects are young men under 35 years of age. This is in contradiction with the peacetime data from the literature on the structure of subjects with knee amputation in relation to age and cause of amputation. Research shows that in peacetime over $80 \%$ of cases are elderly subjects with knee amputations, and the most common cause of amputation are vascular diseases [6].

In our sample, $16.7 \%$ of the subjects with severe war injuries had undergone secondary amputation after an attempt to save the limb and $83.3 \%$ underwent primary amputation. In the literature we find data that in $11 \%$ of subjects where there was an attempt to save the extremity after severe injuries; a secondary amputation has been performed [1].

Our results show that the duration of functional training and prosthetic fitting in subjects with war amputations after severe lower leg injuries is not linearly correlated $(r=-0.102)$ with the time period from wounding to amputation and that the attempt to save the limb and secondary amputation didn't significantly affect the duration of rehabilitation and prosthetic fitting.

\section{CONCLUSION}

Knee amputation is performed as a necessary operation intervention, primarily or secondarily after the rescue attempt to save the extremity, as a result of severe war wounds on the lower extremities. These are most often explosive injuries of land mines. Functional recovery until the gait function is established is not correlated with the time period from the injury until amputation, when it comes to war injuries in which other medical procedures were performed in order to save the extremity extremities. Attempt to save extremities from severe war injuries on the lower leg did not significantly affect the later course of rehabilitation and prosthetic fitting.

\section{ACKNOWLEDGEMENT}

I wanted to thank the colleagues at Trakya University Faculty of Health Sciences, Department of Neurologic
Physical Therapy and Biomechanics Unit, for the help and suggestions during this study, which is a part of our joint SmartLeg project in which we tend to develop a new rehabilitation procedure for people using smart prosthetic devices.

\section{REFERENCES}

[1] Dagum AB, Best AK, Schemisch EH, Mahoney JL, Mahomed MN, Blight KR. Salvage after severe lowerextremity trauma: are the outcomes worth the means? Plast Reconstr Surg 1999; 103: 1212P20.

[2] Kegel B, Carpenter ML, Burgess EM. A survey of lowerlimb amputees: prostheses phantom sensations, and psychosocial aspects. Bull Prosthet Res 1977; 10: 43P60.

[3] Kegel B, Carpenter ML, Burgess EM. Functional capabilities of lower extremity amputees. Arch Phys Med Rehabil 1978; 59: 109P20.

[4] Matsen SL, Malchow D, Matsen FA 3rd. Correlations with patients' perspectives of the Result of LowerExtremity Amputation. J Bone Joint Surg 2000; 82-A,(8) 1089-95.

[5] Simper LB. Below knee amputation in war surgery: a review of 111 amputations with delayed primary closure. J Trauma 1993; 34: 96P8.

[6] Stewart CP, Jain AS. Dundee revisited-25 years of a total amputee service. Prosthet orthot Int 1993; 17: 14-20.

\section{AUTHOR'S BIOGRAPHY}

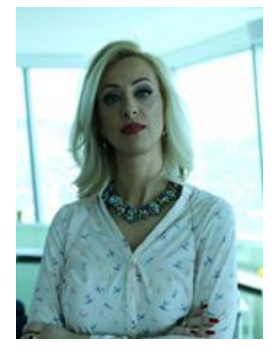

Zlata Jelačić is Assistant Professor in Department of Mechanics at the Faculty of Mechanical Engineering, University of Sarajevo, Bosnia and Herzegovina. $\mathrm{PhD}$ thesis was in the field of rehabilitation robotics, namely the development of active above-knee prosthesis with actuated knee and ankle joints.

\section{Citation of this Article:}

Zlata Jelačić, "Influence of the Primary and Secondary Lower Leg War Amputations on the Length of Hospitalization and Rehabilitation", Published in International Research Journal of Innovations in Engineering and Technology - IRJIET, Volume 6, Issue 1, pp 88-90, January 2022. Article DOI https://doi.org/10.47001/IRJIET/2022.601016 